\title{
Papers
}

\section{Training in flexible, intensive insulin management to enable dietary freedom in people with type 1 diabetes: dose adjustment for normal eating (DAFNE) randomised controlled trial}

DAFNE Study Group

\begin{abstract}
Objectives To evaluate whether a course teaching flexible intensive insulin treatment combining dietary freedom and insulin adjustment can improve both glycaemic control and quality of life in type 1 diabetes. Design Randomised design with participants either attending training immediately (immediate DAFNE) or acting as waiting list controls and attending "delayed DAFNE" training 6 months later. Setting Secondary care diabetes clinics in three English health districts.

Participants 169 adults with type 1 diabetes and moderate or poor glycaemic control.

Main outcome measures Glycated haemoglobin

$\left(\mathrm{HbA}_{1 \mathrm{c}}\right)$, severe hypoglycaemia, impact of diabetes on quality of life (ADDQoL).

Results At 6 months, $\mathrm{HbA}_{1 \mathrm{c}}$ was significantly better in immediate DAFNE patients (mean 8.4\%) than in delayed DAFNE patients $(9.4 \%)(t=6.1, \mathrm{P}<0.0001)$.

The impact of diabetes on dietary freedom was significantly improved in immediate DAFNE patients compared with delayed DAFNE patients $(t=-5.4$, $\mathrm{P}<0.0001)$, as was the impact of diabetes on overall quality of life $(t=2.9, \mathrm{P}<0.01)$. General wellbeing and treatment satisfaction were also significantly improved, but severe hypoglycaemia, weight, and lipids remained unchanged. Improvements in "present quality of life" did not reach significance at 6 months but were significant by 1 year.

Conclusion Skills training promoting dietary freedom improved quality of life and glycaemic control in people with type 1 diabetes without worsening severe hypoglycaemia or cardiovascular risk. This approach has the potential to enable more people to adopt intensive insulin treatment and is worthy of further investigation.
\end{abstract}

\section{Introduction}

Self management is essential to successful treatment of type 1 diabetes, yet few patients alter their insulin from day to day or achieve the degree of glycaemic control known to be ideal. ${ }^{1}$ The diabetes control and complications trial showed the long term benefits of strict glycaemic control. ${ }^{2}$ However, the intensive approach used in the trial involved frequent outpatient visits with close supervision of insulin dose adjustment and has not been incorporated into general diabetes practice. The increased risk of severe hypoglycaemia in the diabetes control and complications trial may be unacceptable, and the staffing ratio of around three patients to each healthcare professional is beyond the scope of most healthcare systems.

Other reasons why intensified treatment has not been widely adopted may exist. Clinicians usually propose treatment goals formulated from the medical perspective, focusing on biomedical outcomes, whereas patients are more concerned about the immediate demands of treatment and how to integrate these into daily life. ${ }^{3}$ Diabetes and its treatment have a negative impact on quality of life, particularly in terms of dietary restrictions imposed by traditional treatment regimens. ${ }^{45}$ It has been argued elsewhere that an approach in which intensive insulin management is used to increase dietary freedom is likely to improve quality of life, ${ }^{6}$ as well as biomedical outcomes, and may result in its wider adoption.

For over 20 years, a team from Dusseldorf has used a five day structured inpatient training programme in intensive insulin treatment, producing sustained improvements in glycaemic control without increasing severe hypoglycaemia. ${ }^{7}$ Participants are taught to match insulin doses to their food choices, while keeping their blood glucose close to normal. In contrast to the diabetes control and complications trial, patients maintain this behaviour with minimal support from healthcare professionals.

We tested this approach in a UK multicentre randomised controlled study, the dose adjustment for normal eating (DAFNE) trial, in which we measured biomedical and psychological outcomes, including quality of life.

\section{Methods}

\section{Participants and protocol}

We recruited patients attending hospital diabetes clinics in Sheffield, Northumbria, and London. We considered patients to be eligible if they were aged over 18
Members of study
group: Stephanie
Amiel, Sue
Beveridge, Clare
Bradley, Carla
Gianfrancesco,
Simon Heller, Peter
James, Natalie
McKeown, Douglas
Newton, Lynn
Newton, Lindsay
Oliver, Helen Reid,
Sue Roberts, Susan
Robson, Jackie
Rollingson, Val
Scott,Jane Speight,
Carolin Taylor,
Gillian Thompson,
Eileen Turner,
Frances Wright
Correspondence to:
S Heller, Clinical
Sciences Centre,
Northern General
Hospital, Herries
Road, Sheffield
S5 7AU
s.heller@
sheffield.ac.uk
bmj.com 2002;325:746

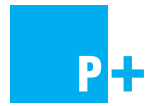

See web extra for details of study group members 
years with clinical features of type 1 diabetes, moderate or poor glycaemic control $\left(\mathrm{HbA}_{1 \mathrm{c}} 7.5-12 \%\right)$, and duration of diabetes of more than two years without advanced complications. Exclusion criteria included inability to understand written and spoken English, severe psychiatric illness, pregnancy, and complete unawareness of hypoglycaemia.

We recruited participants by a single invitation letter sent to all patients identified from clinic registers as fulfilling the eligibility criteria. Respondents were invited to an evening meeting to discuss the DAFNE approach.

After obtaining written informed consent, we randomised volunteers into a waiting list controlled trial, either to attend a five day training course delivered in groups of six to eight participants in each centre (immediate DAFNE) or to continue to receive usual care for six months as controls and then attend a course (delayed DAFNE). We randomised participants by using a computer generated random number list, prepared for each of the three centres. Before recruitment, one researcher in each centre transferred the assignments on to slips of paper and placed them within sealed, opaque envelopes. When provided with lists of names recorded in the order in which participants gave consent, the researchers assigned participants by opening the envelopes in order.

All participants received an explanation of DAFNE principles at enrolment, before courses were held. After participating in a course, patients returned to their usual clinic and, although free to contact the educators for advice, were not offered specific follow up. The local ethics committees of the three hospitals approved the study.

\section{The skills course}

An underlying assumption was that type 1 diabetes is an insulin deficiency disorder, best managed by insulin replacement as needed and not by dietary manipulation to match prescribed insulin. The course provided the skills to enable patients to replace insulin by matching it to desired carbohydrate intake on a meal by meal basis. This was taught as a five day (Monday to Friday) outpatient programme using principles of adult education with explicit learning objectives in a group setting. The educators aimed to build confidence and appropriate independence, with patient autonomy as a goal. Participants were intended to acquire the skills and confidence to adjust insulin to suit their lifestyle rather than being told to adapt the timing and content of meals to more fixed doses of insulin. The educational resources and curriculum were translated by the Dusseldorf team in collaboration with the UK educators.

Two or three educators (diabetes specialist nurses and dietitians) taught the course in each centre. Besides preparing the curriculum and teaching materials, the educators attended a training course run by members of the departments of education of the universities of Newcastle and Durham. Appraisers trained in educational inspection visited one course in each centre to ensure that the course was taught to high standards and was similar between centres. Courses were also peer reviewed by educators from other centres. A nurse educator from Dusseldorf observed and reported formally on at least one day of a course in each centre.

\section{Primary outcomes}

A central laboratory measured glycated haemoglobin $\left(\mathrm{HbA}_{1 c}\right)$ by using a high performance liquid chromatography, diabetes control and complications trial aligned method (Eurogenetic Tosoh 2.2). The top of the reference range for people without diabetes was $6.1 \%$. Patients recorded severe hypoglycaemic episodes (that is, episodes causing coma or requiring the assistance of another person) in blood glucose monitoring diaries.

We used the audit of diabetes-dependent quality of life (ADDQoL) questionnaire to measure the impact of diabetes on quality of life. This tool produces a diabetes impact rating weighted by importance for 18 potentially applicable domains of life, including dietary freedom. ${ }^{5}$ The average weighted impact is a composite score of all applicable domains indicating individualised impact of diabetes on quality of life. Scores for single domains and average weighted impact can range from -9 (maximum negative impact of diabetes) to +9 (maximum positive impact of diabetes). The questionnaire also includes a single item measuring "present quality of life," with scores ranging from -3 (extremely bad) to +3 (excellent).

\section{Secondary outcomes}

We measured satisfaction with treatment by using the diabetes treatment satisfaction questionnaire (DTSQ), ${ }^{8}$ which includes eight items, six of which form a scale (scored 0-36) in which higher scores indicate greater treatment satisfaction. Two individual items (scored 0-6) measure perceived frequency of hyperglycaemia and hypoglycaemia. Higher scores indicate greater perceived frequency. Psychological wellbeing was measured with the 12-item well-being questionnaire (W-BQ12), ${ }^{9}$ which is scored from 0 to 36 , with higher scores indicating better general wellbeing.

Weight was measured by using electronic scales. Blood pressure was measured by using a standard mercury sphygmomanometer, with phase 5 denoting diastolic pressure. Each of the three local laboratories used standard methods to measure serum cholesterol, triglycerides, and high density lipoprotein cholesterol. Patients recorded in their diaries the number of insulin injections, total insulin dose, and blood glucose monitoring.

\section{Analysis}

The study was powered on the expectation that 120 patients would be evaluated. This had $80 \%$ power to detect a difference of $1 \%$ in $\mathrm{HbA}_{1 \mathrm{c}}$ (based on $2 \%$ standard deviation in both groups; $\mathrm{P}<0.05$ two tailed). Data at each time point are expressed as mean (SD). We compared outcomes at six months by using unpaired $t$ tests and 95\% confidence intervals. We checked data for normality and transformed skewed variables by using square root, log, and inverse transformations where appropriate. ${ }^{10}$ We used a $\chi^{2}$ test to compare the proportions of patients experiencing severe hypoglycaemia in the two groups at six months and at 12 months. To examine longer term effects of training in the immediate DAFNE group, we also performed paired $t$ tests with baseline and 12 month data. 


\section{Results}

\section{Recruitment}

We sent letters of invitation to 1016 addresses, and 423 (42\%) forms were returned. Of the 404 patients still living at the address, 299 (74\%) expressed interest in the study and 105 declined. Of these 299, 138 attended an evening meeting, of whom 128 (93\%) decided to participate; another 41 were recruited without attending a meeting. Recruitment stopped when the all the places on the courses had been booked.

\section{Participant flow and follow up}

One hundred and sixty nine patients were randomised, but 27 did not attend a course for reasons such as work commitments (fig 1). These patients did not attend further, so an intention to treat analysis was not possible. Only one person dropped out during a course. One participant in immediate DAFNE was found "dead in bed" six months after the course. One person did not attend the six month assessment, and four people did not attend the 12 month assessment. Thus we analysed data from 140 participants at six months and data from 68 immediate DAFNE participants at 12 months (fig 1). One hundred and thirty six (97\%) participants completed questionnaires at baseline and six months; $62(91 \%$ of 68$)$ participants in the immediate DAFNE group completed questionnaires at baseline and 12 months.

Participants' mean age was 40 (SD 9) years, and the mean duration of diabetes was $16.6(9.6)$ years. Seventy six $(56 \%)$ participants were women. Fifty two (37\%) participants had retinopathy, $19(13 \%)$ had peripheral neuropathy, and two had nephropathy. No significant differences existed between the two groups at baseline in terms of participants' characteristics or primary or secondary endpoints or between the immediate DAFNE group at baseline and the delayed DAFNE group at six months (that is, immediately pre-course).

\section{Primary endpoints}

Table 1 shows the primary outcome data. At six months, $\mathrm{HbA}_{1 \mathrm{c}}$ was significantly improved in the immediate DAFNE group compared with the delayed DAFNE group (clinically important mean improvement of $1 \%$ ). We found no significant difference in the proportion of the immediate DAFNE group who

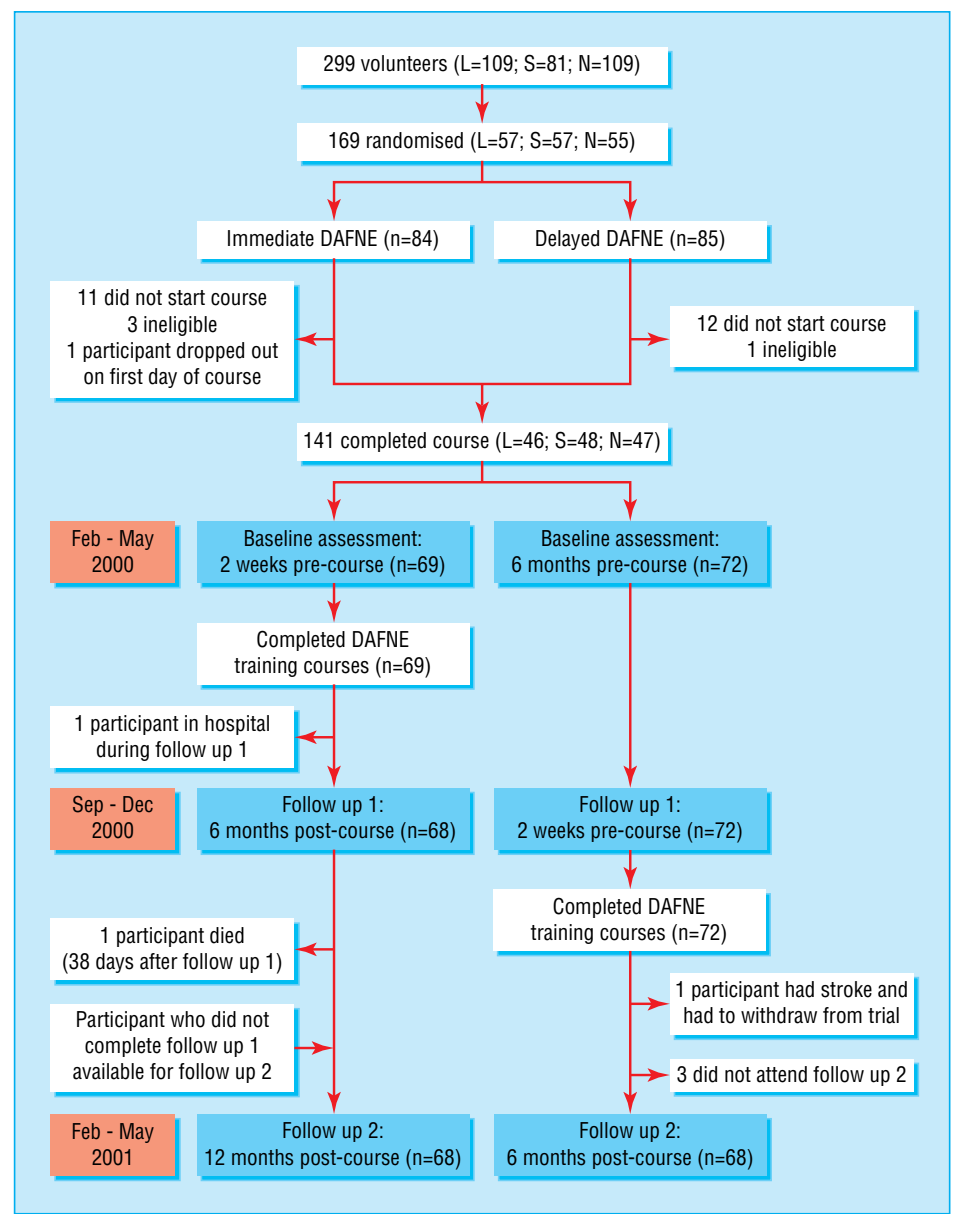

Fig 1 Flow of participants through study (L=London; S=Sheffield; N=Northumbria)

experienced severe hypoglycaemia compared with the delayed DAFNE group. For the quality of life measures, the immediate DAFNE group showed significant improvements in the negative impact of diabetes on dietary freedom in particular ("freedom to eat as I wish score") and the impact on quality of life in general (average weighted impact score) compared with the delayed DAFNE group.

The qualitative data collected illustrate the personal importance of these improvements to participants.

Table 1 Primary outcomes: differences between immediate DAFNE and delayed DAFNE groups at six months. Values are means (standard deviations) unless stated otherwise

\begin{tabular}{|c|c|c|c|c|c|}
\hline \multirow[b]{2}{*}{ Group } & \multirow[b]{2}{*}{$\begin{array}{l}\text { Glycated haemoglobin } \\
\qquad\left(\mathrm{HbA}_{1 \mathrm{c}}, \%\right)\end{array}$} & \multirow{2}{*}{$\begin{array}{l}\text { Proportion of } \\
\text { participants } \\
\text { experiencing severe } \\
\text { hypoglycaemia in } \\
\text { previous six months* } \\
\text { (No (\%)) }\end{array}$} & \multicolumn{3}{|c|}{ Audit of diabetes-dependent quality of life (ADDQoL) } \\
\hline & & & $\begin{array}{l}\text { Weighted impact of } \\
\text { diabetes on "freedom to } \\
\text { eat as I wish" } †\end{array}$ & $\begin{array}{l}\text { Average weighted } \\
\text { impact of diabetes on } \\
\text { quality of life }\end{array}$ & Present quality of lifeł \\
\hline \multicolumn{6}{|l|}{ Immediate DAFNE: } \\
\hline Baseline & $9.4(1.2)$ & 15/68 (22) & $-4.8(2.9)$ & $-2.0(1.6)$ & $1.0(0.9)$ \\
\hline Six months & $8.4(1.2)$ & $12 / 67(18)$ & $-1.8(2.3)$ & $-1.6(1.6)$ & $1.3(0.9)$ \\
\hline \multicolumn{6}{|l|}{ Delayed DAFNE: } \\
\hline Baseline & $9.3(1.1)$ & $8 / 72(11)$ & $-4.0(2.9)$ & $-1.9(1.3)$ & $1.1(0.8)$ \\
\hline Six months & $9.4(1.3)$ & $11 / 72(15)$ & $-4.0(2.8)$ & $-1.9(1.4)$ & $1.0(1.1)$ \\
\hline \multicolumn{6}{|c|}{ Difference between groups at six months } \\
\hline Mean $(95 \% \mathrm{Cl})$ & $1.0(0.5$ to 1.4$)$ & - & $2.2(1.3$ to 3.1$) \S$ & $0.4(-0.1$ to 0.9$) \S$ & $0.3(-0.1$ to 0.6$) \S$ \\
\hline Statistical values & $t=4.4, P<0.0001$ & $\chi^{2}=0.17, P=0.68$ & $t=-5.4, P<0.0001$ & $t=2.9, \mathrm{P}<0.01$ & $t=1.7, P=0.095$ \\
\hline
\end{tabular}

*Percent of participants; $\chi^{2}$ test performed for differences between groups at six months.

$\dagger$ Scored from -9 (maximum negative impact) to +9 (maximum positive impact).

¥Scored from -3 (extremely bad) to +3 (excellent); $0=$ neither good nor bad, $1=$ good, $2=$ very good.

§Confidence interval should be interpreted with caution as variables were transformed before parametric analysis was performed but natural data are reported. 


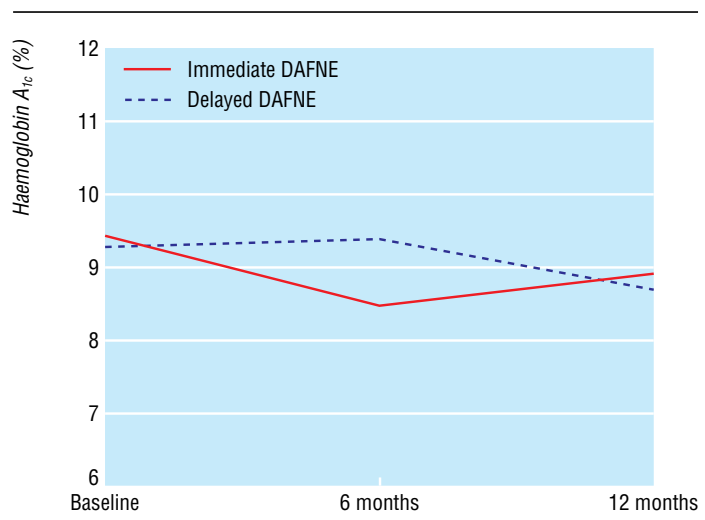

Fig 2 Glycaemic control as measured by glycated haemoglobin $\left(\mathrm{HbA}_{1 \mathrm{c}}\right)$

Examples included "I now feel able to travel abroad without worry about not eating or eating on time" (change in average weighted impact score $=0.28$ ); "I have found my whole lifestyle and outlook on life has improved" (change $=1.08$ ); and "Because I now have better control than ever before I will hopefully cut back on any complications I may have incurred in the future" (change=2.74). The difference in "present quality of life" did not reach significance at six months.

Twelve months after training (assessed only in immediate DAFNE) $\mathrm{HbA}_{1 c}$ remained significantly improved (fig 2) compared with baseline (mean difference $0.5 \%, 95 \%$ confidence interval 0.2 to $-0.9 ; t=3.5$, $\mathrm{P}=0.001)$. One quarter $(16 / 67)$ of participants maintained a fall in $\mathrm{HbA}_{1 \mathrm{c}}$ of $>1.5 \%$, and four $(6 \%)$ showed a rise of $>1.5 \%$. The number of participants experiencing severe hypoglycaemia did not increase significantly.

Improvements in the impact of diabetes on dietary freedom were maintained between six and 12 months (fig 3), with highly significant improvements from baseline to 12 months (mean difference $-2.7,-3.3$ to $-2.1 ; t=10.1, \mathrm{P}<0.0001)$. The impact of diabetes on quality of life in general (average weighted impact score) was further improved (mean difference from baseline to 12 months $-0.7,-1.1$ to $-0.4 ; t=7.2$, $\mathrm{P}<0.0001$ ) (fig 3). "Present quality of life" also continued to improve and reached significance by one year (mean difference baseline to 12 months $-0.5,-0.8$ to $-0.2 ; t=3.6, \mathrm{P}<0.001$ ) (fig 3).

\section{Secondary outcomes}

Table 2 shows the data for the secondary outcomes. We found a significant improvement in psychological wellbeing and satisfaction with treatment at six months and a significant decrease in perceived frequency of hyperglycaemia. Twelve months after training psychological wellbeing had continued to improve to a mean of 24.7 (mean difference from baseline to 12 months -3.6, -5.0 to $-2.2 ; t=-5.0, \mathrm{P}<0.0001)$. Treatment satisfaction remained significantly higher, with a 12 month mean of 31.0 (mean difference from baseline to 12 months $-7.5,-9.1$ to $-5.9 ; t=10.8, \mathrm{P}<0.0001)$. Cardiovascular risk factors and perceived frequency of hypoglycaemia did not change significantly in either group across the trial. Mean blood pressure in the immediate DAFNE group was 133 (SD 16)/79 (9.5) $\mathrm{mm} \mathrm{Hg}$ at baseline and 133 (14)/78 (10) $\mathrm{mm} \mathrm{Hg}$ at 12 months.

The mean number of injections per day increased in both groups after DAFNE training-from 3.6 at baseline to 5.3 at 12 months $(t=10.6, \mathrm{P}<0.001)$ in immediate DAFNE and from 3.5 at baseline to 5.2 at 12 months $(t=13.9, \mathrm{P}<0.001)$ in delayed DAFNE. Average insulin dose increased by a small but significant amount in immediate DAFNE at 12 months compared with baseline (from 0.71 to $0.74 \mathrm{U} / \mathrm{kg} ; t=-2.0$, $\mathrm{P}=0.017$ ) but was unchanged in delayed DAFNE (from 0.71 to $0.70 \mathrm{U} / \mathrm{kg} ; t=0.7, \mathrm{P}=0.47$ ).

\section{Discussion}

Our data show that a structured training course (designed to maintain glucose control while enabling dietary freedom) teaching self management skills to patients with type 1 diabetes was effective over the short term in a British healthcare setting. DAFNE training significantly improved glycated haemoglobin, with no significant increase in severe hypoglycaemia. The training also produced sustained positive effects on quality of life, satisfaction with treatment, and psychological wellbeing, despite an increase in the number of insulin injections and encouragement to increase blood glucose monitoring. Despite increased dietary freedom (as shown by responses to the

Table 2 Secondary outcomes: differences between immediate DAFNE and delayed DAFNE groups at six months. Values are means (SDs) unless stated otherwise

\begin{tabular}{|c|c|c|c|c|c|c|c|c|}
\hline \multirow[b]{3}{*}{ Group } & \multirow[t]{2}{*}{ W-BQ12 } & \multicolumn{3}{|c|}{ Diabetes treatment satisfaction questionnaire (DTSQ) } & \multicolumn{4}{|c|}{ Cardiovascular risk factors } \\
\hline & & \multirow[b]{2}{*}{ Total satisfaction* } & \multicolumn{2}{|c|}{ Perceived frequencyt of: } & \multirow[b]{2}{*}{ Weight (kg) } & \multirow{2}{*}{$\begin{array}{c}\text { Total } \\
\text { cholesterol } \\
\text { (mmol/l) }\end{array}$} & \multirow{2}{*}{$\begin{array}{l}\text { HDL cholesterol } \\
(\mathrm{mmol} / \mathrm{l})\end{array}$} & \multirow{2}{*}{$\begin{array}{l}\text { Triglycerides } \\
(\mathrm{mmol} / \mathrm{l})\end{array}$} \\
\hline & Total wellbeing* & & Hyperglycaemia & Hypoglycaemia & & & & \\
\hline \multicolumn{9}{|l|}{ Immediate DAFNE: } \\
\hline Baseline & $20.94(5.8)$ & $22.88(6.2)$ & $3.57(1.4)$ & $2.04(1.2)$ & $80.5(16.7)$ & $5.2(0.9)$ & $1.5(0.4)$ & $1.5(0.9)$ \\
\hline 6 months & $24.34(5.7)$ & $31.58(3.9)$ & $2.90(1.4)$ & $2.16(1.3)$ & $81.5(16.9)$ & $5.1(0.8)$ & $1.6(0.4)$ & $1.4(0.7)$ \\
\hline \multicolumn{9}{|l|}{ Delayed DAFNE: } \\
\hline Baseline & $21.09(5.8)$ & $23.21(5.8)$ & $3.60(1.6)$ & $2.12(1.4)$ & $77.4(13.4)$ & $4.9(0.8)$ & $1.5(0.5)$ & $1.5(0.9)$ \\
\hline 6 months & $21.37(5.5)$ & $22.82(6.0)$ & $4.03(1.3)$ & $2.40(1.3)$ & $77.3(13.4)$ & $5.0(1.0)$ & $1.5(0.3)$ & $1.5(0.9)$ \\
\hline \multicolumn{9}{|c|}{ Difference between groups at six months } \\
\hline Mean $(95 \% \mathrm{Cl})$ & $\begin{array}{c}2.98 \\
(1.06 \text { to } 4.89)\end{array}$ & $\begin{array}{c}8.75 \\
\text { (7.02 to 10.48)‡ }\end{array}$ & $\begin{array}{c}-1.13 \\
(-1.59 \text { to }-0.67) \\
\end{array}$ & $\begin{array}{c}-0.23 \\
(-0.68 \text { to } 0.21)\end{array}$ & $\begin{array}{c}4.18 \\
(-0.90 \text { to } 9.27) \\
\end{array}$ & $\begin{array}{c}0.15 \\
(-0.16 \text { to } 0.45)\end{array}$ & $\begin{array}{c}0.09 \\
(-0.01 \text { to } 0.22) \\
\end{array}$ & $\begin{array}{c}0.12 \\
(-0.41 \text { to } 0.17) \\
\end{array}$ \\
\hline Statistical values & $t=3.1, P<0.01$ & $t=-10.3, P<0.0001$ & $t=-4.88, \mathrm{P}<0.0001$ & $t=-1.0, P=0.31$ & $t=1.6, P=0.11$ & $t=0.95, P=0.34$ & $t=1.46, P=0.14$ & $t=0.83, P=0.41$ \\
\hline
\end{tabular}

$\mathrm{HDL}=$ high density lipoprotein; $\mathrm{W}$-BQ12=12-item well-being questionnaire.

${ }^{*}$ Scored from 0 to 36 ; a higher score indicates greater wellbeing or satisfaction.

tScored from 0 to 6; a higher score indicates greater perceived frequency of hyperglycaemia or hypoglycaemia.

Confidence interval should be interpreted with caution as variable was transformed before parametric analysis was performed but natural data are reported. 
"freedom to eat as I wish" item in the audit of diabetesdependent quality of life), we observed no deterioration in cardiovascular risk factors. These results are encouraging and suggest that people with established diabetes, when taught appropriate skills, will intensify management of their diabetes and that this can be (and perhaps needs to be) associated with improved quality of life.

As with any randomised controlled trial, a crucial question is how readily the observed effects might be transferred to the wider population of adults with type 1 diabetes. The participants may have been atypical in the impact of diabetes on their quality of life, their dissatisfaction with current treatment, and their willingness to inject insulin five times a day. However, the fact that a third of patients attending routine hospital clinics expressed interest in participating after a single unsolicited advertisement is encouraging. Other studies have shown that current management of
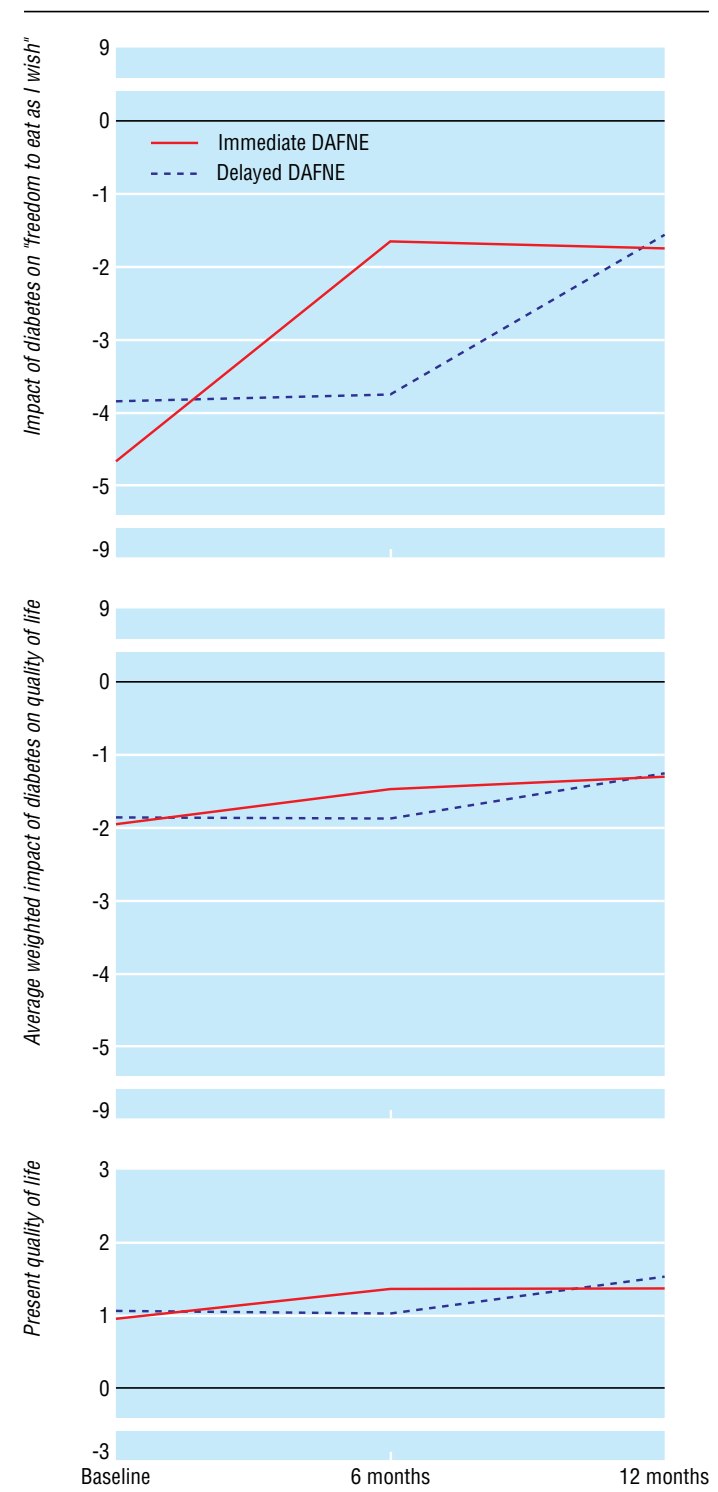

Fig 3 Reported impact of diabetes on "freedom to eat as I wish" (top; $n=123$ ), average weighted impact of diabetes on quality of life (middle; $n=125$ ), and present quality of life (bottom; $n=122$ ) diabetes in the United Kingdom leads to negative effects on quality of life comparable to those seen in our participants at baseline, indicating that many patients with type 1 diabetes stand to benefit from a more flexible approach with increased dietary freedom. ${ }^{45}$ The presentation of the course to patients as a trial may have deterred some, but many patients who are reluctant to participate in research might attend training as part of standard treatment, especially once our findings are known.

Many participants had a relatively long duration of diabetes, with well established, albeit imperfect, strategies for coping with the condition. Patients with a shorter duration of diabetes might prove even more receptive to a flexible, intensive approach. DAFNE training, by facilitating a more flexible lifestyle, might also encourage patients with tight glycaemic control (who were excluded from the trial), particularly those experiencing severe hypoglycaemia, to maintain tight glycaemic targets with greater safety and less damage to quality of life.

The fall in $\mathrm{HbA}_{1 \mathrm{c}}$ at the six month analysis was comparable to that reported in similar interventions. The Dusseldorf group reported a lower $\mathrm{HbA}_{1 \mathrm{c}}$ (by $1.5 \%)$ one year after training, compared with group teaching of diabetes related information alone,,$^{11}$ and similar improvements have been maintained for three and six years. ${ }^{12}{ }^{13}$ We did not see this in the immediate DAFNE group at one year; $\mathrm{HbA}_{1 c}$ rose slightly from the six month value, although it remained statistically and clinically significantly lower than at baseline. The UK participants had a longer duration of diabetes than those in earlier studies and were discharged to a healthcare system unfamiliar with this approach. We avoided proactive follow up by DAFNE educators in order to evaluate the effects of the course alone. We might have expected some deterioration without specific reinforcement or feedback of $\mathrm{HbA}_{1 \mathrm{c}}$

As with any complex intervention, it is difficult to know which aspects contributed to its effect. Control participants received only usual care, and it is possible that the benefits were merely the result of patients spending five days intensively focusing on diabetes, receiving attention from enthusiastic educators. However, the diabetes control and complications trial was unable to show any improvements in quality of life, ${ }^{2}$ and evidence in type 2 diabetes suggests that improvements in audit of diabetes-dependent quality of life scores and $\mathrm{HbA}_{1 \mathrm{c}}$ cannot be achieved by empowerment alone. ${ }^{14}$

Not everyone with type 1 diabetes will wish to undertake intensive insulin treatment, even without dietary restrictions; some will prefer a simpler regimen with routine meal timing and fewer injections. Such options will still be needed. Nevertheless, as the only way of reducing microvascular disease currently is by maintaining tight glycaemic control, we need better ways of enabling patients to intensify their insulin treatment. This study builds on earlier work and shows that skills training and unrestricted food choices can be applied successfully across different healthcare systems. The follow up of our patients was, however, relatively short. We now need to establish whether similar results can be achieved in routine care and devise ways of sustaining improvement in glycaemic control. 


\section{What is already known on this topic}

Current treatment of type 1 diabetes fails to engage many patients in intensive self management and is associated with poor glycaemic outcomes and impaired quality of life

An approach to intensive insulin treatment in which participants match insulin dose to unrestricted food choices has been developed in Germany

This approach has been shown to lead to sustained improvements in glycaemic control but has not been widely adopted elsewhere

\section{What this study adds}

Training in flexible, intensive insulin treatment can improve glycaemic control in the United Kingdom

This approach also leads to significant improvements in treatment satisfaction, psychological wellbeing, and quality of life measures

\section{Conclusion}

We have shown, in a group of volunteers, that skills training in insulin adjustment that provides patients with the ability to fit diabetes into their lives rather than their lives into diabetes improves quality of life and glycaemic control in the short term. The DAFNE approach has the potential to reduce the incidence of microvascular complications and thereby protect quality of life in the long term, as well as the short term, and is worthy of further investigation.

We thank Deborah Rees and Anne Biddles for administrative support and Stephen Walters and John Valentine for statistical advice. We also thank Michael Berger, Ingrid Mühlhauser, Doris Hemman, and Moira Murphy for their support and encouragement throughout the study (Michael Berger died on 17 August 2002). We acknowledge the support of Novo Nordisk UK, which supplemented some of the travel and administrative costs. We thank the patients of King's College Hospital, London, the Northern General and Royal Hallamshire Hospitals in Sheffield, and Northumbria Health Care Trust, who participated in the
DAFNE trial, and those patients' employers who provided paid leave for attendance at a DAFNE course.

Contributors: All members of the DAFNE Study Group developed the ideas for the trial, agreed the study design, recruited the patients, delivered the education courses, and collected the data. SA, CB, SH, PJ, S Roberts, and JS were members of the writing committee; they participated in the data analysis and wrote the paper. SH and JS are the guarantors.

Funding: The DAFNE trial was supported by diabetes development project grants from Diabetes UK to SH, S Roberts, SA (recruitment pilot study: grant no RD99/0001871; feasibility study: grant no RD99/0002057), JS, and CB (grant no RD99/0002058)

Competing interests: None declared.

1 Audit Commission. Testing times: a review of diabetes services in England and Wales. London: Audit Commission, 2000.

2 The Diabetes Control and Complications Trial Research Group. The effect of intensive treatment of diabetes on the development and progression of long-term complications in insulin-dependent diabetes mellitus. N Engl J Med 1993;329:683-9.

3 Wolpert HA, Anderson BJ. Management of diabetes: are doctors framing the benefits from the wrong perspective? BMJ 2001;323:994-6.

4 Bradley C, Todd C, Gorton T, Symonds E, Martin A, Plowright R. The development of an individualized questionnaire measure of perceived impact of diabetes on quality of life: the ADDQoL. Qual Life Res 1999;8:79-91.

5 Bradley C, Speight J. Patient perceptions of diabetes and diabetes therapy: assessing quality of life. Diabetes Metab Res Rev (in press)

6 Bradley C, Pierce MB, Hendrieckx C, Riazi A, Barendse S. Diabetes mellitus. In: Johnston M, Johnston DW, eds. Health psychology. Vol 8 in Bellack AS Hersen M, eds. Comprehensive clinical psychology. Oxford: Elsevier Science, 1998:277-304.

7 Mühlhauser I, Jorgens V, Berger M, Graninger W, Gurtler W, Hornke L, et al. Bicentric evaluation of a teaching and treatment programme for type 1 (insulin-dependent) diabetic patients: improvement of metabolic control and other measures of diabetes care for up to 22 months. Diabetologia 1983;25:476.

8 Bradley C. The diabetes treatment satisfaction questionnaire: DTSQ. In: Bradley C, ed. Handbook of psychology and diabetes: a guide to psychological measurement in diabetes research and practice. Chur, Switzerland: Harwood Academic Publishers, 1994.

9 Bradley C. The 12-item well-being questionnaire: origins, current stage of development, and availability. Diabetes Care 2000;23:875.

10 Tabachnick BG, Fidell LS. Using multivariate statistics. 4th ed. Boston: Allyn and Bacon, 2001.

11 Mühlhauser I, Bruckner I, Berger M, Cheta D, Jörgens V, Scholz V, et al. Evaluation of an intensified insulin treatment and teaching programme as routine management of type 1 (insulin-dependent) diabetes: the Bucharest-Düsseldorf study. Diabetologia 1987;30:681-90.

12 Pieber TR, Brunner GA, Schnedl WJ, Schattenberg S, Kaufmann P, Krejs GJ. Evaluation of a structured outpatient group education program for intensive insulin therapy. Diabetes Care 1995;18:625-30.

13 Bott S, Bott U, Berger M, Mühlhauser I. Intensified insulin therapy and the risk of severe hypoglycaemia. Diabetologia 1997;40:926-32.

14 Kinmonth AL, Woodcock A, Griffin S, Spiegal N, Campbell M] Randomised controlled trial of patient centred care of diabetes in general practice: impact on current wellbeing and future disease risk. BMJ $1998 ; 317: 1202-8$.

(Accepted 29 July 2002) 